\title{
Changes in the extracellular matrix of the clitoris caused by aging: a stereological and comparative study
}

Lucas Alves Sarmento Pires, Monique Silva Dias Babinski, Albino Fonseca Junior, Jorge Henrique Martins Manaia, Marcio Antonio Babinski

Medical Sciences Post Graduation Program, Fluminense Federal University, Rio de Janeiro, Niterói, Brazil

Submitted: 2 September 2021; Accepted: 18 October 2021

Online publication: 29 October 2021

Arch Med Sci 2021; 17 (6): 1816-1818

DOI: https://doi.org/10.5114/aoms/143150

Copyright @ 2021 Termedia \& Banach

\section{Abstract}

Introduction: The clitoris is partially responsible for sexual arousal. The integrity of the extracellular matrix is essential for clitoral erection. Sexual dysfunction is a phenomenon associated with age.

Methods: The clitoris of cadavers of 20- to 80-year-old women was excised and histologically processed. Stereological analysis was performed to quantify the volumetric density of collagen, elastic fibers, and smooth muscle. Results: A significant increase in collagen and a decrease in smooth muscle and elastic fibers were observed in older women.

Conclusions: In short, these changes caused by aging could contribute to female sexual dysfunction concerning clitoral orgasm.

Key words: clitoris, aging, extracellular matrix, stereology.

The clitoris is a well-known organ essential to the female orgasm. It is very similar to the penis as it possesses the same embryological development. The clitoris, however, lacks a corpus spongiosum as it is not related to the urethra. Their similarities mean that the same erection mechanisms occur, although are less expressive in women due to the size of the organ [1].

Approximately, $15 \%$ of women between 45 and 64 years old are prone to have female sexual dysfunction (FSD). This condition is characterized by the presence of one of the following conditions for at least 6 months: significant delay in orgasm, infrequency or complete absence of orgasm, less intense orgasm in $75 \%$ to $100 \%$ of sexual interactions. Its cause is generally multifactorial and includes biological, psychological, and sociocultural factors [2, 3].

Aging is also associated with a decreased sexual response, sexual activity, and libido. Hormonal changes that occur in midlife can affect a woman's sexual function. Menopause is marked by a decline in ovarian hormone levels, which occurs gradually with natural menopause, but can be sudden if menopause occurs because of surgery, radiation, or chemotherapy [4].

It is known that aging affects the extracellular matrix components of several tissues. Older studies have shown that the clitoris of older women is prone to structural changes, which can lead to FSD. The purpose of this study is to quantify the volumetric density of the fibrous elements

\author{
Corresponding author: \\ Lucas Alves Sarmento Pires \\ Medical Sciences Post \\ Graduation Program \\ Fluminense Federal \\ University \\ Rio de Janeiro, Niterói \\ Brazil \\ Phone: 5521983076012 \\ E-mail: lucaspires@id.uff.br
}


of the extracellular matrix of the clitoris in young and old cadavers through stereological methods.

Methods. This research was approved by the local research ethics committee (registry number: 89868318.6.0000.5243). Fragments of the clitoris were obtained from 10 cadavers between 20 and 40 years old (G1) and 10 cadavers over 60 years old (G2). All cadavers were free of any urogenital diseases and died as a result of accidents.

These fragments were processed under routine histological techniques and stained with Masson's trichrome and Weigert's resorcin-fuchsin to observe the fibrous elements of the ECM. Afterward, the volumetric density of the clitoris was calculated by stereological methods with the aid of the M42 grid. Each sample generated five histological slides, and five random fields from each slide were submitted to the stereological analysis (totaling an analysis of 500 histological fields per stain and per group) and the volumetric density of collagen, elastic fibers and smooth muscle was assessed.

Statistical analysis. Statistical analysis was performed with the SPSS 21 software and the $t$-test was used to compare means between groups. A $p$-value $<0.05$ was considered significant. The results are shown as \%mean and standard deviation $( \pm)$.

Results. The mean age of the cadavers from $\mathrm{G} 1$ was $28 \pm 4$ years old, while the mean age of the cadavers from G2 was $75 \pm 6$ years old. The stereological analysis of the collagen content (Figure 1) showed a volumetric density of $24.28 \pm 9.78 \%$ in $\mathrm{G} 1$ and $46.26 \pm 10.89 \%$ in $\mathrm{G} 2(p=0.0038)$. In respect to smooth muscle, the stereological analysis revealed a mean of $41.04 \pm 11.20 \%$ for the $G 1$ and $37.13 \pm 9.07 \%$ for the G2 samples ( $p=0.0217$ ). Regarding the elastic fibers, there was a mean of $36.56 \pm 11.42 \%$ for the $G 1$ and $29.75 \pm 4.17 \%$ for the $\mathrm{G} 2$ samples $(p=0.3467)$.
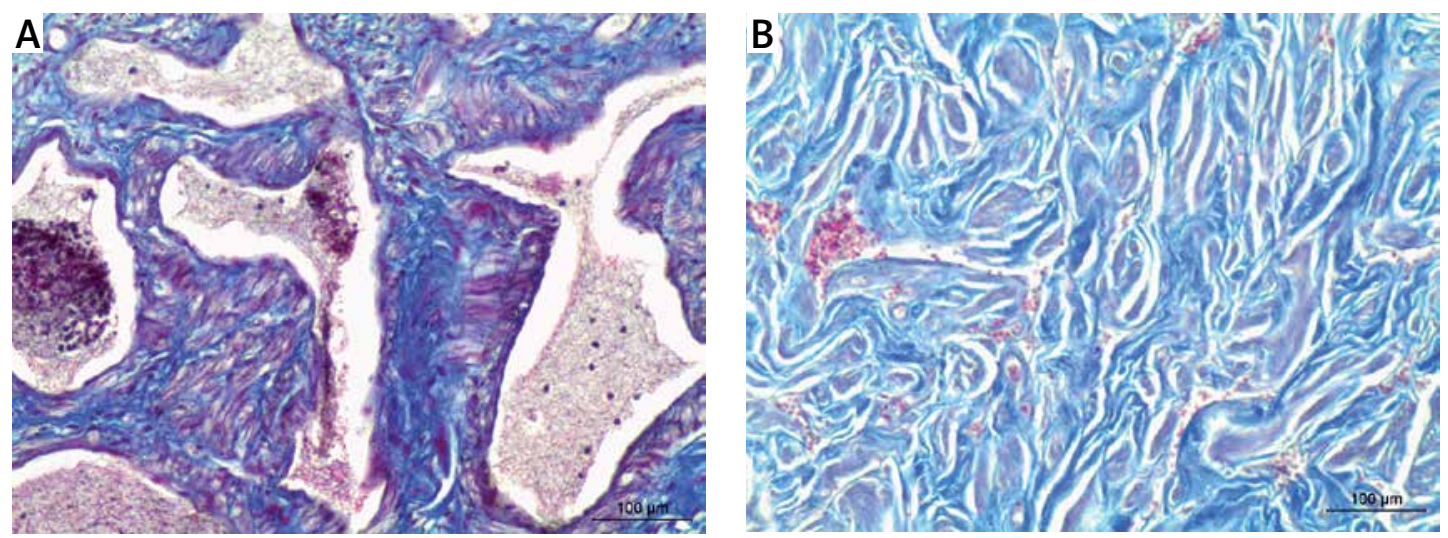

Discussion. Stereology is a known method that aims to quantify elements of a given tissue in a three-dimensional perspective. This means that it considers the tissue as a whole, and not just the photographic record of a histological slide, as conventional histomorphometry proposes. In this sense, stereology aims to reduce observation and routine histological processing biases. It is a more objective method than pure observation and subjective assessment used in histopathology as well $[5,6]$.

Although several authors analyzed the clitoris in women of different ages, no study employed this quantitative resource, which aimed, in the present study, to observe the quantity of collagen, smooth muscle, and elastic fibers in this organ.

Regarding the general histology of the clitoris, we observed results consistent with studies carried out by several authors, which emphasize, therefore, that the clitoris has a pair of corpora cavernosa partially separated by a septum, and both bodies are covered by a thin albugineous tunic. The corpora cavernosa effectively make up the erectile tissue of the clitoris and are formed by irregular sinusoids [7-10].

Tarcan et al. [11] demonstrated age-related changes in the clitoral ECM. The authors employed histomorphometric methods and observed similar results to ours: smooth muscle reduction and collagen increase. Furthermore, the authors observed atherosclerosis in samples belonging to elderly cadavers.

In rabbits, Park et al. [12] observed that there was tissue fibrosis in the clitoris of animals with atherosclerosis as well as a reduction in the lumen of the microvessels that supply the cavernous tissue. The authors also demonstrated that there was a significant loss of smooth muscle, also by histomorphometric methods.

Figure 1. Masson's trichome stain (100x) showing the cavernous tissue of the clitoris in a 23-year-old cadaver (G1) (A) and an 81-year-old cadaver (G2) (B). Notice the trabeculae of the cavernous tissue limiting well the cavernous spaces with a regular amount of collagen and smooth muscle in $\mathrm{G} 1$, while there is a lack of organized trabeculae and sinusoids in G2, as well as a dense collagen network, indicating tissue fibrosis 
Tissue fibrosis was also found in rats submitted to arterial hypertension as seen in the study carried out by Bechara et al. [13]. However, the authors noted that hypertensive rats had a larger vascular lumen in the clitoris and vagina, as well as increased expression of $\alpha$-actin (smooth muscle) and tumor growth factor- $\beta$ in the vascular wall of the clitoral vessels, consistent with hypertension.

Due to this, Bechara et al. [13] raised the hypothesis that an exacerbated hyperplasia of the smooth muscle of the cavernous tissue of the clitoris may cause a disturbance in its function. However, the present study - as well as previously cited papers - have shown a decrease in smooth muscle caused by aging, which is the most likely mechanism for the cavernous tissue's inability to contract and relax harmoniously.

The study performed by Caruso et al. [14] compared the thickness of the smooth muscle of the clitoris of young, pre- and post-menopausal, and diabetic women using histomorphometric analysis from images obtained by scanning electron microscopy. There was a significant reduction in smooth muscle thickness in older women. Women with diabetes and premenopausal women exhibited the lowest mean thickness of the smooth muscle.

Alatas et al. [15] aimed to evaluate the flow of the deep clitoral artery in postmenopausal women who used hormone replacement therapy compared to a control group. The authors noted that hormone replacement significantly increased the blood flow to the clitoris, which can alleviate symptoms of female sexual dysfunction. Replacement therapy aims to manage the changes caused by menopause, including sexual response and libido.

In conclusion, the study presented herein observed by stereological methods that the clitoris of women over 60 years old had an increase in collagen and a decrease in smooth muscle and elastic fibers in comparison to women between 20 and 40 years old. This highlights the negative impact of the aging process on female sexual function.

\section{Conflict of interest}

The authors declare no conflict of interest.

\section{References}

1. Yeung J, Pauls RN. Anatomy of the vulva and the female sexual response. Obstet Gynecol Clin North Am 2016; 43: 27-44.

2. Parish SJ, Hahn SR, Goldstein SW, et al. The International Society for the Study of Women's Sexual Health Process of Care for the Identification of Sexual Concerns and Problems in Women. Mayo Clin Proc 2019; 94: 842-56.

3. Faubion SS, Rullo JE. Sexual dysfunction in women: a practical approach. Am Fam Physician 2015; 92: 281-8.
4. McCool-Myers M, Theurich M, Zuelke A, Knuettel H, Apfelbacher C. Predictors of female sexual dysfunction: a systematic review and qualitative analysis through gender inequality paradigms. BMC Womens Health 2018; 18: 108

5. Kubinova L, Janacek J. Confocal stereology: an efficient tool for measurement of microscopic structures. Cell Tissue Res 2015; 360: 13-28.

6. Brown DL. Bias in image analysis and its solution: unbiased stereology. J Toxicol Pathol 2017; 30: 183-91.

7. Toesca A, Stolfi VM, Cocchia D. Immunohistochemical study of the corpora cavernosa of the human clitoris. J Anat 1996; 188: 513-20.

8. Baskin LS, Erol A, Li YW, Liu WH, Kurzrock E, Cunha GR. Anatomical studies of the human clitoris. J Urol 1999; 162: 1015-20.

9. O'Connell HE, Sanjeevan KV, Hutson JM. Anatomy of the clitoris. J Urol 2005; 174: 1189-95.

10. Pauls RN. Anatomy of the clitoris and the female sexual response. Clin Anat 2015; 28: 376-84.

11. Tarcan T, Park K, Golstein I, et al. Histomorphometric analysis of age-related structural changes in human clitoral cavernosal tissue. J Urol 1999; 161: 940-4.

12. Park K, Tarcan T, Goldstein I, Siroky MB, Krane RJ, Azadzoi KM. Atherosclerosis-induced chronic arterial insufficiency causes clitoral cavernosal fibrosis in the rabbit. Int J Impot Res 2000; 12: 111-6.

13. Bechara AJ, Cao G, Casabe AR, Romano SV, Toblli JE. Morphological modifications in clitoris and vagina in spontaneously hypertensive rats. Int J Impot Res 2003; 15: 166-72.

14. Caruso S, Cianci A, Malandrino C, et al. Ultrastructural and quantitative study of clitoral cavernous tissue from living subjects. J Sex Med 2011; 8: 1675-85.

15. Alatas E, Yagci B, Oztekin O, Sabir N. Effect of hormone replacement therapy on clitoral artery blood flow in healthy postmenopausal women. J Sex Med 2008; 5: 2367-73. 